\title{
TESTING THE EFFICIENCY OF AIR-PHOTO STRATIFICATION USED IN THE NEW BRUNSWICK FOREST INVENTORY
}

\author{
BY A. F. MACPHERSON
}

A. F. Macpherson graduated with a B.Sc. (Forestry) from the University of Edinburgh in 1956. After serving two years in the British Army, he worked until Sept., 1960, as Western Region Forester for the provincial government in Newfoundland. Thereafter he spent a year at the University of New Brunswick, under a Beaverbrook postgraduate fellowship, graduating M.Sc. (Forestry) in October, 1961. The following article is based on work done while at U.N.B. Currently the author is working with the Surveys Division of the B.C. Forest Service with headquarters in Victoria, B.C.

\section{ABSTRACT}

Testing showed that in the New Brunswick Forest Inventory a considerable increase in sampling efficiency, over that of simple random sampling, was obtained by the use of three bases of air-photo stratification within a double sampling framework. These gains were particularly good for total softwood volume, up to $88 \%$ gain being achieved for this volume category. Gains in efficiency for softwood sawlog volume were somewhat disappointing, however, and a modification in sampling design is suggested, which should increase sampling efficiency for this important volume category. Stratification by maturity group was found to be less effective than that by cover type and volume class; the addition of maturity group stratification to that by cover type and volume resulted in little further gain in efficiency.

\section{INTRODUCTION}

The purpose of the tests was threefold. Firstly, to determine by how much the accuracy of estimates of various volume categories was improved, by the use of double sampling and three kinds of photo stratification, over the accuracy attainable from an unrestricted random sample of the same size. Secondly, to judge whether these efficiency gains could be improved by any modification of the sampling design. And thirdly, to determine how the effectiveness of the three kinds of stratification compared with each other, singly and in different combinations.

\section{The Forest InVENToRy Procedure}

A brief description follows of relevant features of the New Brunswick Forest Inventory, which was carried out between 1951 and 1958, and designed by Dr. S. L. Pringle, then of the faculty of Forestry of the University of New Brunswick. Only four out of the five forest districts in the Province are dealt with in this study, as in the first district to be sampled, a different sampling design and stratifications were used. 
Photographs used were of the approximate R.F. 1:15840, taken in the autumn from Fairchild, Eagle 9, or Wild R.C. 5 cameras with lenses of 6 inch focal length, using Kodak super-XX panchromatic film in conjunction with a minus blue filter. A double sampling design was used, the first stage being a systematic series of photo interpretation plots and the second stage a ground sample of a randomly selected number of the interpreted stands.

\section{First Stage Sample}

In the first-stage sample, the stand surrounding every photo centre in the Province was examined stereoscopically, and its boundary marked on the photographs. Stocked, productive forest land was then classed by Cover type, Maturity Group, and Volume Class, as follows:

a) Cover Type

$$
\begin{aligned}
\mathrm{S}-\text { more than } 75 \% \text { softwood by volume } \\
\mathrm{SH}-\text { between } 50 \% \text { and } 75 \% \text { softwood by volume } \\
\mathrm{HS}-\text { between } 25 \% \text { and } 50 \% \text { softwood by volume } \\
\mathrm{H}-\text { less than } 25 \% \text { softwood by volume }
\end{aligned}
$$

b) Maturity Group:

$$
\begin{aligned}
& \text { I - volume } 11 \text { cunits per acre or over, } \\
& \text { largest volume in } 10 \text {-inch plus class } \\
& \text { II - volume } 6 \text { cunits per acre or over, } \\
& \text { largest volume in 6-inch to 9-inch class } \\
& \text { III - volume } 10 \text { cunits per acre or less, } \\
& \text { largest volume in 10-inch plus class } \\
& \text { IV - volume } 10 \text { cunits per acre or less, } \\
& \text { largest volume in 4-inch and } 5 \text {-inch class }
\end{aligned}
$$

c) Volume Class:

$$
\begin{aligned}
& 21+-20.5 \text { cunits per acre or over } \\
& 16-20-\text { between } 15.5 \text { and } 20.5 \text { cunits per acre } \\
& 11-15-\text { between } 10.5 \text { and } 15.5 \text { cunits per acre } \\
& 6-10-\text { between } 5.5 \text { and } 10.5 \text { cunits per acre } \\
& 0-5 \text { between } 0 \text { and } 5.5 \text { cunits per acre }
\end{aligned}
$$

No photogrammetric measurements were taken; the three photo interpreters had available as aids prepared stereograms of stands which had been measured on the ground.

\section{Second-Stage Sample}

From the first-stage sample, estimates were made of the proportion of the forest area falling into each of the 36 cover type/maturity group/volume class combinations. (There were 36 combinations only, as so few plots were classed as 21 t that this volume stratum was later combined with 16-20). From these proportions, or "weights", the numbers of plots required to give the desired accuracy of estimate were calculated by conventional methods, using 
a proportional allocation of plots to strata. These methods are described fully in texts such as those by Bickford, Chapman and Caporaso (1), and Cochran (2). When the number of plots required in each stratum had been calculated, stands in that stratum were selected for ground sampling, using a table of random numbers.

The selected photo-interpreted stands were sampled on the ground as follows: the cruisers went to the stand by the easiest available route and then located the ground strip-sample systematically from the point of easiest access to the stand.

From the above outline, it will be seen that the inventory design involved both random and systematic sampling. The first-stage sample was purely systematic; the second-stage was random in the choice of first-stage plots to be ground-sampled, but systematic in the actual location of the ground sample within the randomly selected stand. In this study, normal statistical methods based on the theory of random sampling are used. This procedure is questionable, but has many precedents. Since any bias introduced by this should equally affect statistics calculated for each method of stratification, the validity of conclusions based on comparisons between these should not be impaired.

\section{Method of InVEstigation}

The gain in efficiency of the stratified two-stage sample over a simple random sample was calculated for some of the more important volume categories--total volume, total softwood volume, softwood sawlog volume, volume in 6 inch to 9 inch class and volume in 4 and 5 inch class. Formulae used were taken from Cochran's "Sampling Techniques" (2). The method compares the variance of the mean for the two-stage stratified sample, with an unbiased estimate of the variance of the mean of a simple random sample. The formulae are:

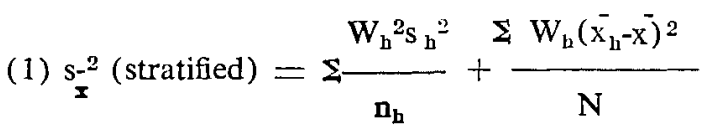

$$
\begin{aligned}
& \text { (2) } \underset{\mathrm{x}}{\mathrm{s}^{2}} \text { (random) }=\frac{\mathrm{N}-\mathrm{n}}{\mathrm{N} \cdot \mathrm{n}}\left\{\Sigma \mathrm{W}_{\mathrm{h}} \mathrm{s}_{\mathrm{h}}^{2}-\frac{\Sigma \mathrm{W}_{\mathrm{h}} \mathrm{s}_{\mathrm{h}}^{2}}{\mathrm{n}_{\mathrm{h}}}+\Sigma \frac{\mathrm{W}_{\mathrm{h}} \mathrm{s}_{\mathrm{h}}^{2}}{\mathrm{n}_{\mathrm{h}}}\right. \\
& \left.+\Sigma W_{h^{i}} \bar{x}_{h}^{2}-\left(\Sigma w_{h} \bar{x}_{h}\right)^{2}\right\}
\end{aligned}
$$

Gain in precision of stratified, over simple random sample:

$$
\text { (3) Gain } \left.=\frac{\frac{s-2}{x}(\text { random })}{s_{x}(\text { stratified })}-1\right\} \times 100 \%
$$


Where:

$$
\begin{aligned}
\mathbf{N}= & \text { size of first-stage sample, i.e., total number of photo-interpreted } \\
& \text { stands in all strata. } \\
\mathbf{n}= & \text { size of second-stage sample, i.e., total number of ground-plots in } \\
& \text { all strata. } \\
\mathrm{n}_{\mathrm{b}}= & \text { number of ground-plots in hth stratum. } \\
\mathrm{W}_{\mathrm{b}}= & \text { proportion of } \mathrm{N} \text { falling in hth stratum, i.e., stratum weight. } \\
\overline{\mathrm{x}}_{\mathrm{b}}= & \text { mean value obtained from sample hth stratum. } \\
\overline{\mathrm{x}}= & \text { mean obtained from stratified sample }\left(\overline{\mathrm{x}}=\mathrm{\Sigma} \mathrm{W}_{\mathrm{b}} \overline{\mathrm{x}}_{\mathrm{h}}\right) \\
\mathrm{s}_{\mathrm{b}}{ }^{2}= & \text { sample variance of hth stratum. }
\end{aligned}
$$

This is essentially the same method as that used by Lawrence and Walker (4) in their investigation in Tasmania, and by Kendall and Sayn-Wittgenstein (3) in their Ottawa Valley experiment.

The study was carried further, and the same technique applied to compare the three-way stratification actually used in the inventory, with other possible stratifications, such as volume class alone, volume class and cover type combined, etc. The variance of the mean obtained by the three-way stratification was compared, using formula 3 , above, with that which would have been obtained if the same plots had been sampled under another stratification. Both variances of the mean were calculated using formula 1. Obviously this test is somewhat biased, as there is no certainty that the same stands would be selected for ground sampling under other possible stratifications, and the statisticians do not provide a formula for an unbiased estimate here as is given by Cochran (2) for the equivalent simple random sample (Formula 2 above). However, in this inventory proportional sampling was used, and a simple random sample tends to distribute itself proportionally among strata (2) and therefore all these proportional samples are approximately comparable with the same simple random sample and hence with each other. Such bias, therefore, was assumed to be slight enough to be ignored.

\section{RESULTS AND DISCUSSION}

\section{Gains in Efficiency}

The gains in efficiency of the two-stage stratified sample over that of a simple random sample of the same size, are shown in table 1.

The meaning of the gains is as follows: for example in the case of total softwood volume in district 1 , to obtain the same accuracy of estimate with a simple random sample as was obtained in the two-stage stratified sample, would require $88 \%$ more ground plots than the 214 actually used in this district. That is, the number of ground plots would have to be increased by 188 to 402 . This, obviously, means that there was considerable financial saving due to stratification within the sampling design-the cost of the 3,307 photo interpretation plots used in this district is negligible compared with that of 188 ground plots. 
TABLE 1

Gains in Efficiency of Stratified Sample over Simple Random Sample

\begin{tabular}{ccccccc}
\hline $\begin{array}{c}\text { Forest } \\
\text { District }\end{array}$ & $\begin{array}{c}\text { No. of } \\
\text { plots }\end{array}$ & $\begin{array}{c}\text { Total } \\
\text { Volume }\end{array}$ & $\begin{array}{c}\text { Total } \\
\text { Softwood } \\
\text { Volume }\end{array}$ & $\begin{array}{c}\text { Softwood } \\
\text { Sawlog } \\
\text { Volume }\end{array}$ & $\begin{array}{c}\text { Volume in } \\
6 \text { to } 9^{\prime \prime} \\
\text { Class }\end{array}$ & $\begin{array}{c}\text { Volume in } \\
4^{\prime \prime} \text { to 5" } \\
\text { Class }\end{array}$ \\
\hline & & & & Percentages & \\
3 & 2017 & 46 & 81 & 10 & 48 & 20 \\
2 & 215 & 36 & 39 & 13 & 15 & 13 \\
1 & 214 & 72 & 88 & 51 & 28 & 19 \\
5 & 218 & 24 & 85 & 18 & 35 & -1 \\
\hline
\end{tabular}

\section{Possible Improvement in Sampling Design}

Study of Table 1 shows that the stratification has been most effective, in all districts, for total softwood volume, and least so for softwood sawlog volume and volume in the 4 inch and 5 inch size class. Since softwood sawlog volume is one of the most important volume categories, it is disappointing that stratification helped relatively little in increasing the accuracy of its estimate. It is felt, however, that this could be improved in future surveys by using "optimum" sampling formulae for calculation of ground plot numbers in each stratum (2), making the number of plots proportional not only to the stratum weight in the population (as is done in "proportional" sampling which was used in the New Brunswick Forest Inventory), but also to the product of stratum weight and the estimated within-stratum standard deviation of softwood sawlog volume. Such a concentration of the sample in high variability strata of high weight would lower the standard error of the estimated district mean softwood sawlog volume per acre.

The effect such a change in sampling design would have on the accuracy of estimates for other volume categories, was considered. It was reasoned that total volume estimates should not be substantially affected as, since within stratum variances of total volume were found to be not significantly different when tested by Bartlett's test, as given by Snedecor in "Statistical Methods" (5), increasing the number of plots in some strata and decreasing it in others, should not affect the overall standard error appreciably, favourably or unfavourably. One would expect the accuracy of total softwood volume estimates to be improved, as it seems reasonable to expect the standard deviation of total softwood volume to be high and low in much the same strata as those in which it is high or low for softwood sawlog volume. One would not expect this to be so for total volumes in the 6 inch to 9 inch, and 4 inch and 5 inch categories, however, and on first consideration it was reasoned that such a change in the sampling design would make one expect reduced gains in efficiency in these categories. fashion.

This reasoning was checked, for forest districts 3 and 5 , in the following 
A mean within-stratum variance was calculated for each volume category, following the method used in Bartlett's test of homogeneity of variance (5). The variances for the various volume categories within the two strataSII 6-10 and SII 11-15-which together constituted a great proportion of the forest $(22 \%$ in district 3 and $18 \%$ in district 5 ) and thus contributed a great proportion of the variance of the mean of the final estimates, were compared with this mean within-stratum variance calculated by Bartlett's method. The results are shown in Table 2.

TABLE 2

Comparisons Between Within-Stratum Variances and Mean Within-STRATUM VARIANCE ${ }^{1}$

\begin{tabular}{|c|c|c|c|c|c|c|c|c|}
\hline \multicolumn{2}{|c|}{ District } & \multirow[t]{2}{*}{ Stratum } & \multirow[t]{2}{*}{ Wh } & \multicolumn{5}{|c|}{$\begin{array}{c}\text { Within-Stratum } \begin{array}{c}\text { Variances (in brackets, mean district } \\
\text { within-stratum variance) }\end{array} \\
\text {. }\end{array}$} \\
\hline & & & & $\begin{array}{l}\text { Softwood } \\
\text { Sawlog } \\
\text { Volume }\end{array}$ & $\begin{array}{c}\text { Total } \\
\text { Volume }\end{array}$ & $\begin{array}{l}\text { Total } \\
\text { Softwood } \\
\text { Volume }\end{array}$ & $\begin{array}{l}6^{\prime \prime} \text { to } 9^{\prime \prime} \\
\text { Volume }\end{array}$ & $\begin{array}{l}4^{\prime \prime} \quad \text { and } 5^{\prime \prime} \\
\text { Volume }\end{array}$ \\
\hline \multirow[t]{2}{*}{3} & SII & $6-10$ & .1044 & $119(49)$ & $20(15)$ & $23(12)$ & $8.4(6.6)$ & $2.081(1.69)$ \\
\hline & SII & $11-15$ & .1219 & $67(49)$ & $11(15)$ & $15(12)$ & $9.0(6.6)$ & $4.01(1.69)$ \\
\hline \multirow[t]{2}{*}{5} & SII & $6-10$ & .0791 & $134(251)$ & $26(30)$ & $29(23)$ & $7.5(6.0)$ & $1.64(1.68)$ \\
\hline & SII & $11-15$ & .1037 & $635(251)$ & $37(30)$ & $38 .(23)$ & $9.7(6.01)$ & $6.52(1.68)$ \\
\hline
\end{tabular}

It will be noted that in all cases except three (total volume in SII 11-15 in district 3; and the total softwood volume and 6" and $9^{\prime \prime}$ volume, both in SII 6-10 in district 5) that where the variance of softwood sawlog volume is higher within these strata than the average, the same is true in all volume categories, and vice versa. Under optimum plot allocation for softwood sawlog volume, the number of plots would be increased over that for proportional allocation in both strata in district 3 , and for SII $11-15$ in district 5 , if this inventory's sample values of stratum variance were taken as estimates. Since, except in one of the three cases mentioned above, this will also mean an increase in plot numbers in high variance strata for the other volume categories, these too would show reduced standard errors of the mean for these most important strata.

This is not exactly what was expected in the preliminary reasoning, and is possibly due to associations between covertype and volumes in the various sizeclass groups. This indicates however that one could expect no substantial decrease in efficiency gains, even for total volumes in the 6 inch to 9 inch class, and 4 inch and 5 inch class, if a plot allocation optimum for softwood sawlog volume were to be used. Indeed, an increase in efficiency gains might even be achieved. The effect on other volume categories not studied might be more unfavourable-the hardwood volumes for instance. However, here again this 
effect need not be substantial. Since at least two ground plots must be assigned to every stratum in order to calculate the standard error, when attempting an optimum allocation for softwood sawlog volume the optimum must be departed from to allocate two plots even to the very low-variance stands in covertype $H$. In no district was the total number of plots in all 9 strata in this cover type more than 45 under proportional allocation-and was as low as 21 in district 2 -and thus optimum allocation could involve no spectacular reduction in plot numbers and increase in stratum standard error in these strata where the highest per acre hardwood volumes occur.

It seems reasonable therefore to suggest that in future surveys using this design in New Brunswick, an optimum allocation of ground plots to forest strata be adopted, based on the estimated standard deviations of softwood sawlog volume within the photo interpreted strata. Any adverse effect on efficiency gains for less important volume categories such as hardwood volumes should be more than compensated for by greater increases in gain in efficiency for the most important categories such as softwood volumes and, of course, especially softwood sawlog volume. The accuracy of estimate of total volume should be substantially unaffected.

\section{Comparison of the Effectiveness of Different Stratifications}

As described under the heading "Method of Investigation", the three-way stratification used in the inventory was compared with other possible stratifications. The results are shown in Table 3.

The chief point of interest apparent from this table is that two-way volume class/cover type stratification was better than the three-way stratification in 8 cases out of 20 , although, except in the case of the softwood sawlog volume in district 1 , these superiorities are very slight. However, where the three-way stratification is superior, it is considerably so only in the cases of 4 inch and 5 inch volume in districts 1,2 and 3 ; total volume in district 2; softwood sawlog volume in districts 2 and 3 ; and 6 inch to 9 inch volume in district 3 .

We may go so far as to say that nothing was gained by the incorporation of maturity group stratification into stratification by cover type and volume class in districts 1 and 5, while gains of value were obtained in district 2 and, more especially, district 3 . Even in districts 2 and 3 however, these gains could not be called great.

Thus maturity group stratification seems to have been of relatively little effect, possibly because the interpreters were not able to differentiate proportion of volume in the size-class groupings consistently on the photographs. It is interesting to note that the forest districts were interpreted in the following order-3, 2, 1 and lastly, 5, in different years. Maturity group interpretation seems to have deteriorated with experience, instead of the reverse: this may however be due to the fact that greater concentrations of sawlog volume were found in the last two districts, and that throughout, maturity group stratification tended to be less effective in reducing standard errors for this category than for the smaller size-classes. Thus the deterioration in effectiveness of maturity group interpretation may be due, in part at least, to having different kinds of stand to interpret. 
TABLE 3

Percentage Gains in Efficiency of 3-Way Stratification over 2 OR 1-WAY STRATIFICATION

\begin{tabular}{|c|c|c|c|c|c|c|}
\hline \multicolumn{2}{|c|}{ Aype of Stratification } & \multirow{3}{*}{$\begin{array}{c}\text { Total } \\
\text { Volume }\end{array}$} & \multicolumn{2}{|c|}{$\begin{array}{l}\text { Total Softwoo } \\
\text { Softwood Sawlog } \\
\text { Volume Volume }\end{array}$} & $\begin{array}{l}\text { de to } 9^{\prime \prime} \\
\text { Volume }\end{array}$ & \multirow[t]{2}{*}{$\begin{array}{l}4^{\prime \prime} \text { and } 5^{\prime} \\
\text { Volume }\end{array}$} \\
\hline & & & \multicolumn{3}{|c|}{ Percentages } & \\
\hline A) & District 3 & & & & & \\
\hline 1) & Volume Class only & -2 & 55 & 16 & 19 & 21 \\
\hline 2) & Maturity Group only & 13 & 65 & 10 & 21 & 21 \\
\hline 3) & Cover Type only & 52 & 34 & 10 & 49 & 29 \\
\hline 4) & Volume Class/Maturity Group & -1 & 52 & 11 & 13 & 9 \\
\hline 5) & Volume Class/Cover Type & 2 & -1 & 6 & 13 & 23 \\
\hline B) & District 2 & & & & & \\
\hline 1) & Volume Class only & 26 & 28 & 0 & 3 & 19 \\
\hline 2) & Maturity Group only & 33 & 40 & -1 & 8 & 10 \\
\hline 3) & Cover Type only & 61 & 26 & 30 & 19 & 15 \\
\hline 4) & Volume Class/Maturity Group & 23 & 31 & -1 & 2 & 3 \\
\hline 5) & Volume Class/Cover Type & 9 & -1 & 10 & -4 & 12 \\
\hline C) & District 1 & & & & & \\
\hline 1) & Volume Class only & 7 & 64 & 24 & 6 & 29 \\
\hline 2) & Maturity Group only & 23 & 74 & 36 & 5 & 17 \\
\hline 3) & Cover Type only & 71 & 54 & 44 & 21 & 24 \\
\hline 4) & Volume Class/Maturity Group & 4 & 66 & 28 & 3 & 13 \\
\hline 5) & Volume Class/Cover Type & -3 & 1 & -11 & -2 & 15 \\
\hline D) & District 5 & & & & & \\
\hline 1) & Volume Class only & 2 & 83 & 17 & 33 & 6 \\
\hline 2) & Maturity Group only & 7 & 86 & 20 & 39 & -6 \\
\hline 3) & Cover Type only & 29 & 22 & 14 & 20 & 0 \\
\hline 4) & Volume Class/Maturity Group & 2 & 81 & 22 & 21 & 0 \\
\hline 5) & Volume Class/Cover Type & 1 & 0 & 0 & -3 & -1 \\
\hline
\end{tabular}

On the other hand, it is striking to note the considerable gains of the three-way stratification over two-way stratification by volume class and maturity group, which occur in most volume categories in all districts; that is, the increase in efficiency by the incorporation of cover type stratification into stratification by volume class and maturity. It was concluded that cover type divided volume class/maturity group strata into strata more homogeneous not only as regards softwood categories, as would be expected, but also for total volume in district 2, 6 inch to 9 inch volume in districts 3 and 5, and 4 inch and 5 inch volume in districts 3 and 1 . This is possibly due to associations 
between cover type and volumes in the various size-class groupings, which were also indicated in section 2 above.

\section{SUMMARY OF CONCLUSIONS}

Three main conclusions emerged from the study.

1) Gains in inventory efficiency, due to the use of three-way stratification and a double sampling design, were considerable in almost all instances investigated. Overall, extensive financial saving is apparent.

2) However, it is considered likely that an optimum allocation of plots to strata, based on estimated within-stratum standard deviations of softwood sawlog volume, would have given increased accuracy over that of the proportional allocation used for important volume categories such as softwood sawlog volume and total softwood volume. There is little reason-due to apparent relationships between proportion of volume by softwood and proportions of total volume by size-classes-that the adverse effect on the accuracy of less important volume categories, such as total volume in the 6 inch to 9 inch and 4 inch and 5 inch classes, would be sufficient to offset this; indeed there might be no loss of accuracy in some of these cases. Loss of accuracy for hardwood estimates should not be great, and accuracy of total volume estimates should be substantially unaffected.

3) There was considerable weakness in the maturity group stratification, the addition of maturity group stratification to that by cover type and volume class achieving little overall gain in accuracy for the volume categories studied. What gains were achieved were confined to two districts, and tended to be concentrated in the less important volume categories. This is probably due to difficulty experienced by the interpreters in classifying stands consistently on the basis of the proportion of total volume in the various size-class groupings.

\section{ACKNOWLEDGEMENTS}

Thanks are extended to Mr. B. M. Smith of the photogrammetry branch, Department of Lands and Mines, Fredericton, who made available the data, and to Mr. K. B. Brown, Deputy Minister, for allowing publication of this article. Thanks are also extended to Dr. S. L. Pringle, formerly of the Faculty of Forestry, University of New Brunswick, who suggested the study and gave valuable advice; and to Associate Professor W. H. Hilborn, University of New Brunswick, who supervised the project.

\section{REFERENCES}

1) BICKFORD, C. A., CHAPMAN, R. A. and CAPORA5O, A. P. 1952. Report of cooperative test of Continuous Inventory Forest Survey System in Eastern Maryland. N. E. Forest Experimental Station.

2) COCHRAN, W. G. 1953. Sampling Techniques. John Wiley and Sons Inc., New York.

3) KENDALL, R. H. and SAYN-WITTGENSTEIN, L. 1961. A test of the Effectiveness of Air-Photo Stratification. Forestry Chronicle Vol. 37, No. 4.

4) LAWRENCE, P. R. and WALKER, B. B. 1954. Methods and Results of Forest Assessment Using Random Sampling Units in Photo-Interpreted Strata. Australian Forestry, Vol. 18, No. 2 .

5) SNEDECOR, G. W. 1956. Statistical Methods (5th Edition), Iowa State College Press, Ames, Iowa. 